\title{
COOPERAÇÃO FINANCEIRA REGIONAL: UMA AVALIAÇÃO SOBRE O FUNDO LATINO-AMERICANO DE RESERVAS E O PAPEL DO BRASIL
}

\author{
Marcelo Pereira Fernandes ${ }^{1}$ \\ Rubia Cristina Wegner ${ }^{2}$
}

\begin{abstract}
Resumo: Entre as formas de acordos monetários está o fundo regional de reservas. Este possui entre as suas principais atribuições servir como colchão de liquidez para países envoltos em crises de balanço de pagamentos ou cambiais, minimizando os efeitos de uma fuga de capitais. A América Latina já possui um fundo regional em funcionamento, denominado Fundo Latino-Americano de Reservas (FLAR). Todavia é um fundo com recursos limitados, logo é pouco eficaz em lidar com crises de grande magnitude. Daí a necessidade de sua ampliação para que possa atender as economias da região. Durante os governos Lula e Dilma (2003-2015) o processo de integração na América do Sul ganhou um novo alento. Todavia, apesar da retórica integracionista das autoridades brasileiras nesse período, o país pouco contribuiu para ampliação do FLAR.
\end{abstract}

Palavras-chave: Cooperação; Fundo Regional de Reservas; FLAR; Integração; Brasil

\section{REGIONAL FINANCIAL COOPERATION: AN EVALUATION ON THE LATIN AMERICAN RESERVE FUND AND THE ROLE OF BRAZIL}

\begin{abstract}
Among the forms of monetary arrangements is the regional reserve fund. This has among its main tasks serve as liquidity cushion for countries wrapped in balance of payments crises or exchange, minimizing the consequences of capital flight. Latin America has already a functioning regional reserve fund called the Latin American Reserve Fund (FLAR). However, it is a fund with limited resources, which is therefore hardly effective in dealing with major crises. Hence the need for its expansion so that it can serve as economies of the region. During the Lula and Dilma governments (2003-2015) the process of integration in South America has gained new impetus. However, despite the integrationist rhetoric of the Brazilian authorities during this period, the country did little to expand FLAR.
\end{abstract}

Key-Words: Cooperation; Regional Reserve Fund; FLAR; Integration; Brazil

\section{COOPERACIÓN FINANCIERA REGIONAL: UNA EVALUACIÓN SOBRE EL FONDO LATINOAMERICANO DE RESERVAS Y EL PAPEL DEL BRASIL}

Resumen: Una de las formas de acuerdos monetarios es el fondo regional de reservas. Un fondo regional tiene entre sus principales atribuiciones servir como un soporte de liquidez

\footnotetext{
${ }^{1}$ Professor do Departamento de Economia da UFRRJ. Universidade Federal Rural do Rio de Janeiro (UFRRJ). Email: mapefern@gmail.com.

${ }^{2}$ Professora do departamento de Economia. Universidade Federal Rural do Rio de Janeiro (UFRRJ). Email: rubicawegner@gmail.com.
} 
para sus países que están en envoltos en crisis en saldo de pagos, minimizando los efectos de una fuga de capitales. La América Latina cuenta con un fondo regional activo, que se llama Fondo Latino-Americano de Reservas (FLAR). Pero es un fondo con activos limitados, pues, el fondo tiene pocas posibilidades en el manejo de una crisis de gran magnitud, por ejemplo. Ocurre una necesidad de su ampliación incluyendo todas las economías de la región. Durante los gobiernos Lula y Dilma (2003-2015) el proceso de integración económica en América del Sur ganó un nuevo ritmo. Todavia, mismo con la retórica integracionista de las autoridades brasileñas en este período, el país poco ha contribuido com la ampliación del FLAR.

Palabras Clave: Cooperación; Fondo de Regional de Reservas; FLAR; Integración; Brasil

\section{INTRODUÇÃO}

O sistema monetário internacional experimenta um período fértil de cooperação financeira e arranjos monetários entre países. Esta onda pode ter iniciado primeiramente pelo advento do Euro, mas também foi estimulada pela sequência de crises financeiras vivenciadas na segunda metade da década de 1990 e que culminou com a crise financeira norte-americana e, posteriormente, internacional, iniciada em 2007. Além disso, processos econômicos de integração regional contribuíram para respaldar tais iniciativas. A América Latina não apenas não passou incólume por esse fenômeno como possui experiência com arranjos desse tipo ${ }^{3}$.

Entre as formas de cooperação financeira, podemos citar o Fundo Regional de Reservas (doravante, FRR) (FRITZ; MÜHLICH, 2012). Este possui entre as suas principais atribuições servir como colchão de liquidez para os países envoltos em crises de balanço de pagamentos ou cambiais, minimizando os efeitos de uma fuga de capitais. Assim, quando administrado corretamente, o FRR é um importante mecanismo de defesa, contribuindo para manter a estabilidade financeira regional. O FRR é um instrumento que pode facilitar a adoção de um regime macroeconômico condizente com as necessidades de desenvolvimento dos países que compõem o acordo, tornando-os menos dependentes dos ciclos do mercado financeiro internacional. Além disso, ao contribuir com a estabilidade financeira na região, os países beneficiados estarão mais aptos a adotar políticas econômicas pró-crescimento, com geração de emprego e distribuição de renda, o que consequentemente deverá aumentar o espaço nacional ou regional para a formulação de políticas de inserção na economia mundial que modifiquem suas relações com as economias centrais.

\footnotetext{
${ }^{3}$ Desde a década de 1950 a CEPAL preocupava-se com a formação de um mercado comum na América Latina. A necessidade de ganhos de escala para consolidar processos de industrialização em países com mercados domésticos pequenos levava a necessidade de maior integração econômica da região. A criação de Sistemas de Pagamentos Regionais era visto como um suporte a esta estratégia. Ver CEPAL [1959] (2000).
} 
A América Latina já possui um FRR em funcionamento, denominado Fondo Latino americano de Reservas (FLAR). Todavia é um fundo com recursos limitados, sendo bastante questionável sua eficácia em lidar com crises financeiras da magnitude daquelas que assolaram a América Latina nas últimas décadas. Notavelmente, é justamente no apoio destinado a responder a necessidades de financiamento do balanço de pagamentos uma das áreas mais frágeis da cooperação financeira na região (TITELMAN, 2006).

Nessa perspectiva, não é surpreendente que, em dezembro de 2008, o presidente equatoriano Rafael Correa, durante a Cúpula de Chefes de Estado do Mercado Comum do Sul (MERCOSUL), defendeu a criação de um fundo de reservas com a finalidade de fazer frente à crise financeira internacional (ALMEIDA; JUNGBLUT, 2012). O então presidente venezuelano Hugo Chávez na primeira reunião da Comunidade de Estados LatinoAmericanos e Caribenhos (CELAC) ocorrida em dezembro de 2011 em Caracas, também sugeriu aos chefes de estado um fundo de reservas para região (GIRALDI, 2011). É importante ressaltar que tanto o Equador quanto a Venezuela fazem parte do FLAR desde 1978 (GIRALDO, 2012). Ainda em 2011, durante reunião da União de Nações Sulamericanas (UNASUL), Guido Mantega, Ministro da Fazenda do Brasil, anunciou que o país iniciaria conversas para adesão ao FLAR.

De fato, desde meados dos anos 1990 já existia uma forte percepção que a atual arquitetura financeira internacional precisa ser reformada (OCAMPO, 2006). Contraditoriamente, muito pouco se avançou desde então, ainda que o Fundo Monetário Internacional (FMI) tenha virado alvo de críticas tanto da esquerda quanto da direita do espectro político pela sua atuação na crise asiática de 1997-1998 e na crise financeira de 2008-2009 (FERNANDES, 2012). O entendimento que tem prevalecido é o de atenuar os erros com o objetivo de melhorar o funcionamento do sistema financeiro ao invés de questionar seus pressupostos. Porém, em que pese às dificuldades de reforma, as economias sul-americanas podem avançar numa nova arquitetura financeira regional já que este é um fator essencial para a integração regional, e a criação de um fundo de reservas ou a ampliação do FLAR pode cumprir um papel de destaque nesse sentido.

A região passou relativamente bem pela crise internacional de 2008-2009, apesar da queda do crescimento econômico. De fato, não ocorreram maxidesvalorizações no câmbio de qualquer moeda, algo incomum quando comparado a outras crises em que tais economias se defrontaram. Uma das razões responsáveis pela menor vulnerabilidade está justamente na 
redução da percepção de risco em razão do estoque de reservas internacionais que a região acumulou nos últimos tempos. No entanto, a força das economias sul-americanas diante dessa crise, por se tratar de uma exceção na história, não serve de base para o futuro. A conjuntura atual já apresenta um quadro menos favorável em relação àquele que prevalecia até o princípio da década de 2010. Em verdade, a região continua muito exposta às intempéries do mercado financeiro internacional.

Este artigo possui dois objetivos principais. Em primeiro lugar discutir o FLAR, destacando suas possibilidades como instituição pertinente para cumprir os desígnios de um fundo de reservas. E, em segundo lugar, analisar o papel do Brasil diante do FLAR. Desde a ascensão de governos progressistas em 2003, o Brasil adotou uma retórica claramente integracionista, tanto na esfera econômica como na esfera política. No entanto, isso não se traduziu na construção de um FRR que de fato cumprisse uma função de relevo no cenário regional. Após essa introdução, na segunda seção discutiremos a função de um fundo regional de reservas no contexto da cooperação financeira regional. Na terceira seção analisaremos o FLAR - primeiro e único fundo de reservas da região - quanto aos seus indicadores e sua atuação junto à estabilidade de seus países membros. Na quarta seção discutiremos a posição do Brasil diante do FLAR. Apresentaremos breves considerações na parte final.

\section{FUNDO REGIONAL DE RESERVAS E O FORTALECIMENTO DAS ECONOMIAS REGIONAIS}

A coordenação macroeconômica é considerada, do ponto de vista da literatura convencional, uma etapa necessária para o avanço em direção a formas mais profundas de integração, como o mercado comum e, mais ainda, a unificação monetária. Podemos entender por coordenação macroeconômica a harmonização de critérios das políticas monetária, físcal e cambial, buscando maior convergência entre as economias, implicando, necessariamente, em modificação significativa na forma como são conduzidas as políticas nacionais, em nome da interdependência entre as economias do bloco regional (FISCHER, 1987). Na verdade, e mesmo que não se tenha como objetivo constituir uma união monetária, justifica-se a tentativa de coordenação macroeconômica no âmbito de um acordo regional em função da existência de certa interdependência entre os países membros, dado que as opções de política econômica tomadas isoladamente por um país afetarão todos os demais. Dathein (2007) aponta que, analogamente ao que acontece na esfera nacional, é muito difícil a adoção de políticas de 
desenvolvimento em âmbito regional se houver sérios problemas macroeconômicos concentrando as atenções dos governos.

Nesse sentido, o estabelecimento de um FRR, tendo como principal função fornecer um seguro contra crises no balanço de pagamentos e cambiais pode contribuir com a coordenação macroeconômica dos países que fazem parte do bloco regional. A ideia relativamente simples é que em períodos de calmaria os governos realizam aportes de capital ao fundo, e retiram em momentos de turbulência, seja como prevenção ou para contenção de uma desvalorização cambial descontrolada devido a um choque externo (CÉSAR, 2012, p.119). Para isso, precisa existir um compromisso entre os associados que acelere a provisão de liquidez com taxas de juros relativamente baixas (DULLIEN ET AL, 2013, p.12).

Desse modo, em razão da velocidade com que os efeitos deletérios de uma fuga de capitais costumam se propagar pela economia ${ }^{4}$, o FRR tem a vantagem de ser mais ágil e flexível em relação às instituições internacionais que provém liquidez (FRITZ; MÜHLICH, 2012, p.13). Um acordo de contingência do FMI, por exemplo, pode demorar meses de negociação até que seja concluído (AGOSIN, 2013, p.8). Logo, o FRR atua incialmente como complemento às instituições financeiras internacionais, e num horizonte mais distante, como a primeira alternativa dos países que necessitem de liquidez com urgência.

A formação de um FRR pode melhorar o manejo das reservas internacionais ao permitir baixar o custo de carregamento de reservas de cada país. Isso ocorre por pelo menos dois motivos. Primeiramente porque reduz a quantidade necessária de reservas que os bancos centrais precisam manter individualmente a fim de arcar com as obrigações do país, em especial as de curto-prazo (YEYATI, 2012; AGOSIN, 2013); em segundo lugar, porque ao passo que o fundo se torne efetivo, o risco de um ataque especulativo provavelmente diminui, assim como a taxa de juros.

Todavia, o uso do FRR como seguro contra crises somente funciona se este não for utilizado por todos os países ao mesmo tempo. Nessa mesma direção, Titelman et al (2013) e Agosin (2013) compreendem que um pré-requisito fundamental para assegurar a viabilidade e sustentabilidade de um fundo de reservas, é que as crises que os países membros do fundo

\footnotetext{
${ }^{4}$ Historicamente os fluxos de capitais tem apresentado um caráter pró-cíclico. Nos momentos de euforia a entrada de capitais tende a ser excessiva, valorizando o câmbio com todos os efeitos negativos sobre o balanço de pagamentos (CEPAL, 2000).
} 
enfrentam não tenham um caráter sistêmico. Isto é, que a probabilidade de todos os países solicitarem socorro simultaneamente seja reduzida.

De tal modo, uma das opções para avaliar o grau de gravidade quando as crises de balanço de pagamentos são simultâneas está em investigar algumas variáveis, tais como: alterações nos termos de troca, mudanças no estoque de reservas internacionais e os fluxos líquidos de capital; e a partir daí calcular utilizando coeficientes de correlação simples (AGOSIN; HERESI, 2011; TITELMAN ET AL, 2013). Assim sendo, coeficientes de correlação positivos e estatisticamente significativos implicam que os países são afetados simultaneamente por choques, o que enfraquece os argumentos para a constituição de um Fundo. Ao contrário, correlações negativas reforçam os argumentos a favor do Fundo. Existem também correlações positivas, mas não significativas, apontando na direção da viabilidade do Fundo, pois, neste caso, os choques afetam os países com intensidade diferente; aqueles menos afetados têm menos necessidade de recorrer ao Fundo. Os cálculos realizados por Agosin e Heresi (2009) e Titelman et al (2013) chegaram a resultados semelhantes, demostrando que para América Latina a constituição de um FRR é perfeitamente factível.

Por outro lado, segundo Agosin (2013, p.5), quando as crises são sequenciais a capacidade de enfrentamento do FRR é maior, uma vez que uma ação rápida, quando a crise começa a se manifestar, pode impedir que o efeito contágio se estenda para outros países. De qualquer forma é inegável que um FRR não é um instrumento totalmente eficaz, em especial numa crise simultânea cuja gravidade, como foi a do leste asiático em 1997-1998, fizesse com que todos os associados precisassem de socorro financeiro ao mesmo tempo.

Do mesmo modo, é essencial considerar, em primeiro lugar, a capacidade financeira do Fundo. É óbvio que quanto maior a sua capacidade, maior também é a possibilidade de atender ao bloco regional. Além disso, o FRR faz parte de um conjunto de instituições que integram a arquitetura financeira internacional. E a sua utilização não elimina o uso de alternativas, como acordos de swap entre bancos centrais ou empréstimos de instituições multilaterais. Por sua vez, ao contar com a garantia de uma rede de financiamento, os países associados tendem a melhorar a qualificação de risco, reduzindo as taxas de juros de seus empréstimos (AGOSIN, 2013, p.7).

Os benefícios do FRR também variam de acordo com o tamanho dos países. As economias menores geralmente se beneficiam mais; enquanto as maiores são menos 
favorecidas, pois os recursos financeiros acessíveis normalmente são menores que as suas necessidades de liquidez no momento de reação ao choque externo. O problema é que são as economias maiores que detém a maior capacidade de contribuir financeiramente com o fundo (DULLIEN ET AL, 2013, p.12). Nesse caso, como veremos mais à frente, o caso do Brasil é exemplar.

Outra vantagem importante a considerar é que o FRR pode ser constituído mesmo com um baixo nível de coordenação macroeconômica regional (FRITZ; MUHLICH, 2012, p.14). Ao mesmo tempo, um FRR também contribui para a coordenação macroeconômica da região na medida em que cria um novo fórum de discussões a respeito do tema, além de ajudar a manter um cenário econômico mais estável (TITELMAN, 2006). A volatilidade excessiva das taxas de câmbio, por exemplo, tem resultados deletérios sobre o crescimento econômico, a alocação de investimentos e o comércio na região, dificultando a construção de acordos entre os países (BAER; SILVA, 2015). Some-se a isso que, em situações de emergência as oportunidades de acordos com perspectivas de longo prazo tornam-se mais difíceis.

\section{O FUNDO LATINO-AMERICANO DE RESERVAS}

\section{Funcionamento}

Atualmente a América Latina já possui um fundo de reservas em funcionamento, o FLAR ${ }^{5} \mathrm{~A}$ instituição conta com oito países membros. São eles: Bolívia, Colômbia, Costa Rica, Equador, Paraguai, Peru, Venezuela e o Uruguai. Com sede em Bogotá, Colômbia, a governabilidade do FLAR foi estabelecida da seguinte forma: a Assembleia de Representantes, composto pelos ministros da fazenda de cada país, que se reúnem uma vez por ano; o Diretório, composto pelos presidentes dos bancos centrais de cada país; a Presidência Executiva, órgão técnico permanente e o representante legal da organização. $O$ presidente executivo atua como presidente do Diretório, mas sem direito a voto ${ }^{6}$; e a Equipe de Gestão, formada pela Secretaria Geral, a Gestão de Riscos, a Gestão Financeira, a Direção de Estudos Econômicos, Pesquisa e Desenvolvimento e a Gestão Administrativa.

\footnotetext{
${ }^{5}$ O fundo foi criado em 1978 com o nome de Fondo Andino de Reservas (FAR) a fim de que a Comunidade Andina pudesse contar com uma instituição financeira própria. Em 1989 o FAR se transformou no FLAR com o propósito de permitir a participação de todos os países latino-americanos. O Paraguai é o seu sócio mais recente, tendo aderido em 2015.

${ }^{6}$ Atualmente a Presidência Executiva é ocupada por Ana María Carrasquilla desde 2011. Em 2014 ela foi reeleita para o cargo.
} 
O FLAR tem ainda segundo o seu Convênio Constitutivo (FLAR, 2016), como objetivos principais:

i) Socorrer os associados com concessão de créditos no momento de uma crise externa;

ii) Melhorar as condições de investimento das reservas internacionais assumidos pelos países associados;

iii) Contribuir para a harmonização das políticas cambial, monetária e financeira dos países associados.

Os empréstimos são efetuados de maneira proporcional à contribuição de cada banco central associado, com condicionalidades mínimas ou mesmo inexistentes ${ }^{7}$. Isso garante que os trâmites para transferência de recursos sejas relativamente rápidos (TITELMAN ET AL, 2013, p.29; VERGARA, 2012; VELARDE, 2014, p.148). No entanto, a fim de não comprometer a sua solvência ou rating de crédito, o nível de alavancagem é baixo. Os países com maior dimensão econômica devem ter um capital mínimo de US\$ 250 milhões, enquanto os menores devem ter um capital mínimo de US\$ 125 milhões. Há ainda a possibilidade dos países de pequena dimensão fazerem aportes de capital abaixo do limite. Neste caso, poderão dividir uma cadeira com outros países sempre que os respectivos capitais somarem o capital mínimo (FLAR, 2016, p.11).

Somado à contribuição dos países membros, o FLAR também capta recursos no mercado financeiro e aceita depósitos à vista e, desde 2006, também depósitos a prazo dos bancos centrais (CÉSAR, 2012, p.127). O FLAR também disponibiliza serviços de assessoria e assistência técnica aos bancos centrais dos países membros e instituições financeiras regionais, além de promover cursos, seminários e conferências. A Direção de Estudos Econômicos acompanha o desempenho macroeconômico dos países membros e de seus sistemas financeiros, publicando análises periódicas que contêm informações sobre o cenário macroeconômico desses países (CARRASQUILLA, 2014, p. 207; CÉZAR, 2012, p.132).

\footnotetext{
${ }^{7}$ Conforme exposto em documento da instituição: "El Banco Central solicitante presenta al Presidente Ejecutivo del FLAR una exposición sobre las medidas de política monetaria, crediticia, cambiaria, fiscal y de comercio exterior que las autoridades nacional es correspondientes han adoptado, y pretenden adoptar para corregir o atenuar los desequilibrios de balanza de pagos que luego es estudiada por el Directoriodel FLAR. El FLAR analisa el programa económico presentado por el país solicitante y presenta un informe al Directorio. Por regla general, el Directorio del FLAR siempre ha avalado el programa presentado por el respectivo Banco Central sin solicitar condicionalidades adicionales para otorgar créditos." (FLAR, 2016, p.34).
} 
Atualmente o FLAR conta com uma qualificação de AA (longo prazo) y A-1+ (curto prazo) da Standard \& Poor's, e de Aa2 da Moody's.

Cada membro possui um assento com direito a um voto na Assembleia de Representantes, composto pelos ministros da Fazenda, e no Diretório, representando pelos presidentes dos bancos centrais (GIRALDO, 2012). A instituição possui na atualidade cinco modalidades de crédito (FLAR, 2016, p.29-31):

i) Crédito de auxílio ao balanço de pagamentos. Tem o objetivo de fortalecer a posição das reservas internacionais como política para retomar a capacidade de pagamento do país. O prazo é de três anos com um ano de carência.

ii) Reestruturação de dívida externa dos bancos centrais. Direcionada para atender as necessidades extraordinárias de divisas. O prazo é de três anos com um ano de carência.

iii) Crédito de liquidez. Tem como objetivo ajudar a aumentar as reservas internacionais em situações de pressões especulativas e expectativas negativas sobre o mercado de câmbio. O prazo é de até um ano.

iv) Crédito contingente. Destinado aos bancos centrais para facilitar o processo de renegociação da dívida externa do setor público. O prazo é de até seis meses.

v) Crédito de Tesouraria. O objetivo é atender às necessidades de liquidez de curtíssimo prazo. Os prazos variam de 1 a 30 dias.

\section{Desafios da Atuação do FLAR}

O FLAR, devido à agilidade na concessão de empréstimos tem servido como um instrumento anticíclico relevante para os países associados, como ressalta Titelman (2006). Em alguns momentos, durante a crise da dívida externa nos anos de 1980, o FLAR assumiu como o único emprestador, ajudando a reduzir os desequilíbrios nas contas externas em meio à crise. Ainda de acordo com Ocampo (2014, p.162) quanto à ajuda financeira, o FLAR superou o FMI em vários períodos não apenas nos anos críticos da crise da dívida externa, mas também na crise das economias emergentes no fim dos anos 1990 e começos dos 2000, e na recente crise financeira internacional. 
Todavia, em relação à principal atribuição de um fundo de reservas - o socorro financeiro em momentos de crise no balaço de pagamentos e crises cambiais - o FLAR está muito limitado em razão da sua baixa capacidade financeira: a instituição possui cerca de US\$ 3,9 bilhões de capital subscrito e US\$ 2,8 bilhões de capital integralizado, segundo informações de abril de 2017. A instituição provavelmente teria uma função reduzida, por exemplo, numa crise que atingisse simultaneamente a Colômbia e a Venezuela, as maiores economias sócias.

Tabela 1 - Estrutura de Capital do FLAR

\begin{tabular}{|r|c|c|c|}
\hline \multicolumn{2}{|c|}{ Capital Subscrito } & Capital Pago ${ }^{\mathbf{1}}$ \\
\hline País & Milhões & $\%$ Total & Milhões \\
\hline Bolívia & 328,1 & $8,6 \%$ & 245,3 \\
\hline Colômbia & 656,3 & $17,2 \%$ & 490,6 \\
\hline Costa Rica & 656,3 & $14 \%$ & 402,0 \\
\hline Equador & 328,1 & $8,6 \%$ & 245,3 \\
\hline Paraguai & 328,1 & $8,6 \%$ & 244,9 \\
\hline Peru & 656,3 & $17,2 \%$ & 490,6 \\
\hline Uruguai & 328,1 & $8,6 \%$ & 245,8 \\
\hline Venezuela & 656,3 & $17,2 \%$ & 490,8 \\
\hline Total & 3937,5 & $100 \%$ & $\mathbf{2 8 5 5 , 3}$ \\
\hline Reserva Prudencial & & & 285,5 \\
\hline
\end{tabular}

1. 30 de abril de 2017

Fonte: FLAR

Há atualmente em curso propostas que visam ampliar o FLAR, o que aumentaria seus recursos disponíveis (TITELMAN, 2013). Todavia, sua ampliação esbarra em dificuldades relacionadas à governança institucional. Uma proposta que incluísse Brasil e Argentina e que pretendesse aumentar significativamente o capital da instituição, provavelmente encontraria alguma resistência quanto ao sistema de votos vigente da instituição - principio de "um país, um voto" - que não discrimina pelo valor dos aportes financeiros.

Historicamente os países membros nunca ficaram inadimplentes (GIRALDO, 2012). Porém, o FLAR tem uma estrutura de empréstimo conservadora e rígida que pode ser mais um entrave à entrada das grandes economias da região (GONZÁLEZ, 2012, p.32). Basta 
recordar que somente na crise do Brasil em 1998-1999 foi necessário um suporte financeiro de US\$ 41 bilhões do FMI. Na realidade, as autoridades responsáveis pelo FLAR ainda concebem uma instituição que complemente a atuação das grandes instituições financeiras, como o FMI (AGOSIN, 2013; VERGARA, 2012). Ou seja, um fundo que cumpra, no máximo, um papel secundário enquanto fonte de liquidez.

Recentemente, o FLAR ampliou seu capital devido à decisão da Costa Rica em aumentar sua participação. Mas a diferença ainda é muito pequena. A baixa coordenação macroeconômica não elimina a possibilidade de constituição do Fundo, como observamos na seção anterior. Porém, a baixa capacidade do Fundo também não contribui para o avanço na coordenação, passo essencial para progredir no processo de integração.

No geral os países sul-americanos mantiveram durante os anos 2000 superávits em transações correntes, acumularam reservas internacionais, logo reduzindo a vulnerabilidade externa, conforme podemos observar nas tabelas abaixo. 
FERNANDES, WEGNER

\section{Tabela 2 - Dívida Externa Total (\%PIB)}

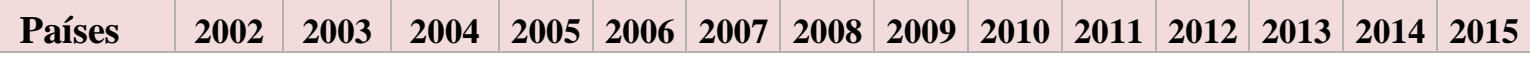
\begin{tabular}{lllllllllllllll} 
Argentina & 141,7 & 117,2 & 103,2 & 52,7 & 48,6 & 43,3 & 34,4 & 35,5 & 31,4 & 27,4 & 25,1 & 23,1 & 25,5 & 24,1 \\
\hline
\end{tabular} $\begin{array}{llllllllllllllll}\text { Bolívia } & 88,2 & 95,7 & 86,2 & 80,3 & 54,8 & 41,2 & 35,6 & 33,5 & 29,9 & 26,3 & 24,5 & 25,3 & 25,9 & 28,6\end{array}$ \begin{tabular}{lllllllllllllll} 
Brasil & 41,3 & 38,5 & 30,1 & 19,0 & 15,6 & 13,8 & 11,7 & 11,9 & 11,6 & 11,4 & 13,3 & 12,7 & 14,6 & 18,9 \\
\hline
\end{tabular} \begin{tabular}{llllllllllllllll} 
Chile & 57,0 & 55,3 & 43,2 & 37,1 & 32,1 & 31,0 & 35,4 & 42,2 & 39,1 & 39,6 & 45,4 & 48,6 & 57,8 & 64,6 \\
\hline
\end{tabular}

\begin{tabular}{lllllllllllllll} 
Colômbia & 38,2 & 40,2 & 33,7 & 26,3 & 24,7 & 21,5 & 19,0 & 23,1 & 22,6 & 22,5 & 21,3 & 24,2 & 26,8 & 37,9 \\
\hline
\end{tabular}

\begin{tabular}{lllllllllllllll} 
Costa Rica & 30,7 & 31,0 & 30,2 & 33,0 & 31,1 & 29,9 & 28,8 & 27,5 & 25,6 & 26,7 & 33,1 & 39,5 & 43,2 & 44,1 \\
\hline
\end{tabular}

\begin{tabular}{lllllllllllllll} 
Equador & 56,9 & 51,7 & 47,0 & 41,5 & 36,5 & 34,2 & 27,4 & 21,6 & 20,0 & 19,2 & 18,1 & 19,8 & 23,6 & 27,1 \\
\hline
\end{tabular}

\begin{tabular}{llllllllllllllll} 
Paraguai & 45,8 & 44,8 & 36,1 & 29,4 & 24,6 & 19,8 & 17,4 & 19,9 & 18,5 & 15,8 & 18,6 & 16,5 & 19,8 & 24,0 \\
\hline
\end{tabular} \begin{tabular}{lllllllllllllll} 
Peru & 50,9 & 50,4 & 46,8 & 37,3 & 32,0 & 32,5 & 29,0 & 29,1 & 29,6 & 27,9 & 30,8 & 30,2 & 32,1 & 36,1 \\
\hline
\end{tabular}

\begin{tabular}{llllllllllllllll} 
Uruguai & 82,2 & 94,2 & 83,9 & 79,0 & 66,3 & 63,5 & 50,8 & 56,8 & 45,7 & 38,2 & 46,9 & 46,1 & 49,1 & 53,2 \\
\hline
\end{tabular}

\begin{tabular}{lllllllllllllll} 
Venezuela & 38,2 & 48,4 & 38,8 & 31,9 & 24,4 & 25,4 & 21,1 & 25,7 & 42,7 & 37,4 & 34,3 & 35,6 & 28,1 & 11,2 \\
\hline
\end{tabular}

Fonte: CEPAL

Tabela 3 - Saldo em Conta de Transações Correntes (\% PIB)

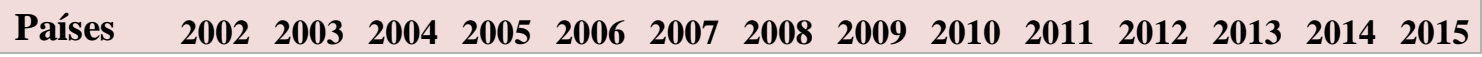

\begin{tabular}{lllllllllllllll} 
Argentina & 7,9 & 5,7 & 1,9 & 2,5 & 3,2 & 2,5 & 1,8 & 2,4 & $-0,4$ & $-0,8$ & $-0,2$ & $-2,0$ & $-1,4$ & $-2,5$ \\
\hline
\end{tabular} \begin{tabular}{lllllllllllllll} 
Bolívia & $-4,5$ & 1,0 & 3,8 & 6,5 & 11,5 & 12,1 & 12,1 & 4,3 & 3,9 & 0,3 & 7,3 & 3,4 & 1,4 & $-5,6$ \\
\hline
\end{tabular} \begin{tabular}{lllllllllllllll} 
Brasil & $-1,5$ & 0,7 & 1,7 & 1,6 & 1,2 & 0,1 & $-1,7$ & $-1,5$ & $-3,4$ & $-2,9$ & $-3,0$ & $-3,0$ & $-4,3$ & $-3,3$ \\
\hline
\end{tabular} \begin{tabular}{lllllllllllllll} 
Chile & $-0,8$ & $-1,1$ & 1,8 & 3,7 & 5,6 & $-3,4$ & 2,6 & 1,0 & $-3,5$ & $-4,1$ & $-0,9$ & $-1,8$ & $-1,3$ & $-2,0$ \\
\hline
\end{tabular} \begin{tabular}{lllllllllllllllll} 
Colômbia & $-1,3$ & $-1,0$ & $-0,7$ & $-1,3$ & $-1,8$ & $-2,9$ & $-2,6$ & $-2,0$ & $-3,0$ & $-2,9$ & $-3,0$ & $-3,2$ & $-5,1$ & $-6,5$ \\
\hline
\end{tabular} \begin{tabular}{lllllllllllllll} 
Costa Rica & $-5,0$ & $-4,9$ & $-4,1$ & $-4,8$ & $-4,4$ & $-6,1$ & $-9,1$ & $-1,9$ & $-3,3$ & $-5,4$ & $-5,2$ & $-4,9$ & $-4,9$ & $-4,3$ \\
\hline
\end{tabular} \begin{tabular}{lllllllllllllll} 
Equador & $-4,3$ & $-1,2$ & $-1,3$ & 1,1 & 3,7 & 3,2 & 6,0 & $-1,9$ & $-2,3$ & $-0,5$ & $-0,2$ & $-1,0$ & $-0,5$ & $-2,1$ \\
\hline
\end{tabular} \begin{tabular}{lllllllllllllll} 
Paraguai & 9,8 & 0,3 & $-0,1$ & $-0,8$ & 1,6 & 5,6 & 1,1 & 3,8 & 0,2 & 0,8 & $-1,2$ & 2,1 & 0,1 & $-1,1$ \\
\hline
\end{tabular} $\begin{array}{lllllllllllllll}\text { Peru } & -2,0 & -1,6 & 0,1 & 1,5 & 3,3 & 1,5 & -4,4 & -0,5 & -2,4 & -1,8 & -2,7 & -4,3 & -4,1 & -4,9\end{array}$ \begin{tabular}{lllllllllllllll} 
Uruguai & 3,0 & $-0,7$ & 0,0 & 0,2 & $-2,0$ & $-0,9$ & $-5,7$ & $-1,2$ & $-1,8$ & $-2,7$ & $-5,1$ & $-5,0$ & $-4,5$ & $-2,3$ \\
\hline
\end{tabular} \begin{tabular}{lllllllllllllll} 
Venezuela & 8,2 & 14,1 & 13,8 & 17,5 & 14,4 & 5,8 & 9,9 & 0,1 & 2,3 & 5,2 & 0,7 & 1,2 & 0,7 & $-1,5$ \\
\hline
\end{tabular} Fonte: CEPAL

\section{Tabela 4 - Reservas Internacionais (em milhões US\$)*}

\begin{tabular}{rccccccccccc}
\multicolumn{1}{c}{ Países } & $\mathbf{2 0 0 6}$ & $\mathbf{2 0 0 7}$ & $\mathbf{2 0 0 8}$ & $\mathbf{2 0 0 9}$ & $\mathbf{2 0 1 0}$ & $\mathbf{2 0 1 1}$ & $\mathbf{2 0 1 2}$ & $\mathbf{2 0 1 3}$ & $\mathbf{2 0 1 4}$ & $\mathbf{2 0 1 5}$ & $\mathbf{2 0 1 6}$ \\
\hline Argentina & 32037 & 46176 & 46386 & 47967 & 52145 & 46231 & 43290 & 30599 & 31443 & 25563 & 38772 \\
\hline Paraguai & - & - & - & - & 2622 & 2957 & 2482 & 4360 & 3949 & 2495 & 4258 \\
\hline Uruguai & 3091 & 4121 & 6360 & 7987 & 7656 & 10302 & 13605 & 16290 & 17555 & 15634 & 13472 \\
\hline Equador & - & - & 3711 & 2846 & 1387 & 1597 & 469 & 3088 & 3237 & 1884 & 3721 \\
\hline Costa Rica $^{1}$ & 3114 & 4113 & 3799 & 4066 & 4627 & 4755 & 6856 & 7330 & 7211 & 7834 & 7573 \\
\hline Venezuela $^{2}$ & 37740 & 34286 & 43127 & 35830 & 30332 & 29892 & 29890 & 21481 & 22080 & 16370 & 10995 \\
\hline Colômbia & 15435 & 20948 & 24029 & 25355 & 28451 & 32300 & 37466 & 43632 & 47323 & 46731 & 46674 \\
\hline Bolívia & 3177 & 5319 & 7722 & 8580 & 9729 & 12018 & 13926 & 14430 & 15122 & 13055 & 10081 \\
\hline Peru & 17275 & 27689 & 31196 & 33135 & 44105 & 48816 & 63991 & 65663 & 62308 & 61485 & 61686 \\
\hline Brasil & 85839 & 180334 & 206806 & 239054 & 288574 & 352012 & 378613 & 375793 & 374050 & 368738 & 372221 \\
\hline BCRA & & & & & & & & & & &
\end{tabular}

Fonte: BCRA (Argentina); BCB (Brasil); BCU (Uruguai); BCV (Venezuela); BANREP (Colômbia);

BCCR (Costa Rica); BCV (Venezuela); BCP (Paraguai); BCE(Equador)

* Média em dezembro de cada ano

${ }^{1}$ Reservas liquidas 
Nessa conjuntura o interesse pela constituição de um fundo de reservas tende a diminuir em razão de uma visão de curto prazo. Mas contraditoriamente é justamente nesse momento em que é mais viável a sua constituição. Num cenário de dificuldades econômicas internas e/ou externas torna-se praticamente impossível qualquer medida nesse sentido.

Sem um FRR que sirva efetivamente as economias sul-americanas em momentos de crise, essas permanecem dependentes do FMI, o que deveria servir de alerta, assim como serviu para as economias da Ásia ${ }^{8}$ desde a sua atuação desastrada na crise que varreu o continente (1997-1998) ou mesmo pela forma ineficiente como respondeu a crise de 20082009 (FERNANDES, 2012).

\section{A POSIÇÃO DO BRASIL}

Desde a eleição de Lula em 2003 o processo de integração da América do Sul ganhou um reforço importante, uma vez que as autoridades brasileiras passaram a apontar notadamente para uma politica externa de aproximação com os países da região. De fato, houve avanços no processo de integração com a constituição de instrumentos como o Fortalecimento Institucional do MERCOSUL (FOCEM) e o MERCOSUL Social, além de avanços importantes nas relações comerciais e a criação da UNASUL. Entretanto, a constituição de um FRR que atendesse as economias sul-americanas apenas foi cogitado.

Quanto ao FLAR, provavelmente a adesão do Brasil, dado seu peso na região, estimularia a participação da Argentina e do Chile, ajudando a alavancar enormemente o Fundo. Porém, a postura do Brasil foi vacilante durante o governo Lula (2003-2010), não tendo demonstrado maior interesse, justamente quando a retórica pró-integração era mais contundente.

\footnotetext{
${ }^{8} \mathrm{Na}$ Ásia, a crise de 1997-1998 teve como consequência a Iniciativa de Chiang Mai. A conferência que ocorreu em 2000 na Tailândia deu origem a um conjunto de diretrizes acertados entre os países da Associação das Nações do Sudeste Asiático (ASEAN) mais a República Popular da China, Japão e a Coreia do Sul. E entre essas diretrizes estava a decisão de criar um fundo conjunto de reservas internacionais composto pelos países envolvidos na conferência. Em 2010 foi lançado o FRR da Iniciativa com um aporte de US\$ 120 bilhões. Em 2012 foi ampliado para US\$ 240 bilhões. Sua criação representou uma resposta à evasiva atuação do FMI na região, bem como uma alternativa a todas as posições de ativos em dólar assumidas pelos países da região. É válido lembrar que os bancos centrais dos países da ASEAN desde 1977 mantinham acordos sobre swaps. (Ver: http://asiancenturyinstitute.com/economy/248-chiang-mai-initiative-an-asian-imf).
} 
A proposta de adesão ao FLAR começou a ser discutida efetivamente no decorrer do governo Dilma (2011-2015), embora sem maiores avanços. Em agosto de 2011 durante uma reunião com ministros da Economia e presidentes de Bancos Centrais dos doze membros da UNASUL em Buenos Aires, em que se debatia a crise nos Estados Unidos e na União Europeia, o então Ministro da Fazenda Guido Mantega anunciou que o FLAR pretendia incluir o Brasil entre seus sócios, e que haveria por parte do governo brasileiro uma sinalização positiva. Segundo Mantega: "Ficou combinado que o FLAR fará uma série de viagens por vários países e virá ao Brasil, para que possamos discutir as condições para podermos ingressar no fundo". E disse ainda que: "Podemos pensar em aumentar o número de países membros do FLAR para que ele possa ter maior poder de fogo". Uma das condições para a entrada do Brasil no fundo seria o pagamento de uma cota de US\$ 500 milhões, valor relativamente irrisório para um país que na época possuía cerca de US\$ 352 bilhões em reservas internacionais (Tabela 4). Mantega também mencionou a iniciativa dos países asiáticos, como exemplo a ser seguido (FERRAZ, 2011; FELÍCIO, 2011).

Ainda em agosto de 2011 no âmbito dos Grupos de Trabalhos instituídos na reunião do Conselho da UNASUL, a Secretaria de Assuntos Internacionais do Ministério da Fazenda, juntamente com técnicos do Banco Central, participou de um Grupo de Trabalho (GT1) coordenado pelo Equador e a Colômbia. Este tinha o intuito de propiciar ações de cooperação técnica referente à administração e mobilização de reservas internacionais. Com isso, avaliava-se a possibilidade de expansão do FLAR para fomentá-lo como instrumento regional.

Em 2014, através do Grupo Técnico de Integração Financeira (GTIF) - grupo designado pelo Conselho Sul-americano de Economia e Finanças (CSEF) da UNASUL com a finalidade de investigar e aprovar ações que promovam a integração econômica regional - foi aprovado a realização de um estudo sobre a possibilidade de expansão do FLAR (SAIM, 2015). No ano seguinte, o GTIF continuou a trabalhar na perspectiva de expansão do Fundo (SAIM, 2016).

Do mesmo modo, o Banco Central recentemente buscou se aproximar da Instituição, seja fazendo visitas técnicas à sede ou participando de Conferências como o XXVIII FLAR's Reserves and Sovereign Funds Conference ocorrida em 2014, promovida pelo FLAR. Pelo menos até 2015, o Banco Central esteve atento à possibilidade de expansão do FLAR por 
meio da entrada do Brasil, como atesta seu relatório de gestão de 2015, mas sem maior efetividade.

Portanto, na contramão de iniciativas recentes de acordos entre países em desenvolvimento para fortalecer sua posição financeira externa ${ }^{9}$, o Brasil não deu suporte a criação de um fundo de reservas que atendesse a América do Sul. Nem mesmo a efetividade do Banco do Sul enquanto emprestador, o Brasil apoiou ${ }^{10}$. Todos os países do fundo mais o Brasil, Argentina e o Chile são membros da UNASUL, logo, mantêm projetos de infraestrutura na carteira do Conselho Sul-Americano de Infraestrutura e Planejamento (COSIPLAN). A base para o financiamento de longo prazo desses projetos, após 10 anos da primeira carteira de projetos, ainda não está estabelecida a contento. Exceto pelo Brasil, que se destaca regionalmente com o Banco Nacional de Desenvolvimento Econômico e Social (BNDES), embora sua atuação tenha se restringido a financiar as grandes empresas brasileiras que atuaram em obras desses projetos de investimento. Em um contexto como esse, aprofundar uma iniciativa como o FLAR - via maiores aportes da maior economia da região, o Brasil - poderia ser um mecanismo a mais (ou complementar) para fortalecer a posição financeira desses países, ao reduzir vulnerabilidade e limitação do balanço de pagamentos, por exemplo.

\section{CONSIDERAÇÕES FINAIS}

O FLAR como está atualmente constituído tem aplicação limitada, longe em relação ao que a América do Sul realmente necessita para enfrentar os desafios que impõe a atual arquitetura financeira internacional e que provavelmente não será reformada num futuro próximo. O Fundo não somente representaria um instrumento financeiro importante contra crises financeiras, como também sinalizaria a vontade política de seus integrantes em avançar no processo de integração, atraindo novos sócios. Sem exigir tanta articulação entre os países,

\footnotetext{
${ }^{9}$ Fazemos referência mais uma vez ao acordo de cooperação financeira regional no Sudeste Asiático - a Iniciativa de Chiang Mai.

${ }^{10}$ Furtado (2008) relata as negativas do Brasil aos pleitos de Equador e Peru quanto ao tamanho e funcionamento do Banco do Sul. O Brasil se justificava afirmando que a região já contava com instituições que tinham funções emprestatícias, como o atual Banco de Desenvolvimento da América Latina (CAF). Naquele momento, 2007, o Brasil e os demais países do MERCOSUL ampliaram sua participação na CAF, porém. Havia ainda, como esclarece Furtado (2008), o objetivo de o BNDES ampliar sua atuação regional.
} 
a sua constituição acarretaria maiores possibilidades de coordenação macroeconômica, dando um novo impulso ao desenvolvimento econômico na região.

No entanto, mesmo que questões técnicas a respeito da constituição de um FRR sejam levadas em conta, a decisão política dos países envolvidos é o que em ultima instância prevalece. Na América do Sul, essa decisão caberia principalmente ao Brasil, país que na última década passava por uma conjuntura de crescimento econômico com distribuição de renda, e mantinha suas contas externas em posição confortável. Embora o país não lograsse benefícios diretos, a adesão traria vantagens para as economias menores e mais vulneráveis da região, contribuindo diretamente para o fortalecimento da integração em acordo com a estratégia de política internacional inaugurada no começo do governo Lula. Nesse sentido, havia condições econômicas e políticas bastante promissoras nos anos 2000 para a ampliação do FLAR, mas ao contrário dos países asiáticos, faltou a decisão política de fazê-lo por parte da liderança principal da região. E, no momento, já não há qualquer indicação para que isto ocorra num futuro próximo.

\section{REFERÊNCIAS BIBLIOGRÁFICAS}

AGOSIN, Manuel R. (2013). Um Fondo Monetario Latinoamericano: Dimensiones $\begin{array}{lllll}\text { Requeridas } & \mathbf{y} & \text { Modalidades. } & \text { Disponível } & \text { em }\end{array}$ https://www.flar.net/contenido/contenido.aspx?catID=152\&conID=6927 . Acesso em: $12 / 2014$.

AGOSIN, Manuel R; HERESI, Rodrigo (2011). Hacia um Fondo Monetario Latinoamericano. FLAR, Paper sand Proceedings. Conferencia de Estúdios Económicos de2010.

ALMEIDA, Cássia; JUNGBLUT, Cristiane (2012). "Presidente do Equador propõe criar fundo de reservas de países da América Latina". $O$ Globo, 31 de janeiro. Disponível em:< http://oglobo.globo.com/economia/presidente-do-equador-propoe-criar-fundo-de-reservas-depaises-da-america-latina-3801882> . Acesso em 02/2015.

BAER, Werner e SILVA, Peri (2015). MERCOSUL: Its Successes and Failures During Its First Two Decades. Latin American Business Review, 15:3-4.

BANCO CENTRAL DA BOLÍVIA (2015) Administración de las Reservas Internacionales - primer semestre 2015. Disponível em: https://www.bcb.gob.bo/?q=pub_informes-sobre-inversion >. Acesso em: 02/2016.

BANCO INTERAMERICANO DE DESSARROLO (BID) (2011). Informe Mercosur n⿳16. Banco Interamericano de Desarrollo: instituto para laintegracíon da América Latina y el Caribe - $\quad$ BID-INTAL. Disponível em: http://idbdocs.iadb.org/wsdocs/getdocument.aspx?docnum=3669446> . Acesso em: 03/2016 BISSETT-TOM, Kelli A; DUBREUIL, Elie Heriard (2013). Fondo Latinoamericano de Reservas. Standard \& Poor's, Ratitngs Services. Disponível em: https://www.flar.net/documentos/7291_S\&P_FLAR_Analysis.pdf >. Acesso em: 03/2015. 
CARRASQUILLA, Ana Maria (2014) Los últimos diez año sy el futuro del FLAR. In: PERRY, Guillermo (ed). Construyendo um Fondo Latinoamericano de Reservas: los 35 años del FLAR. Bogotá: Fondo Latinoamericano de Reserva.

CEPAL (2015). Estudio Económico de América Latina y el Caribe: desafíos para impulsar el ciclo de inversión con miras a reactivar el crecimiento. Disponível em: <http:// http://ww.cepal.org/> . Acesso em: 05/2016.

CEPAL [1959] (2000). A Significação do Mercado Comum no Desenvolvimento

Econômico da América Latina. In: Bielschowsky, Ricardo (org.). Cinquenta Anos de Pensamento na CEPAL. Record

CEPAL (2006) “Estudio Económico de América Latina yel Caribe- 2005-2006”.

Disponível em: 〈http:// http://ww.cepal.org/> . Acesso em:12/2014.

CEPAL (2000). "Equidad, Desarrollo y Ciudadanía", Naciones Unidas, Comisión para America Latina y el Caribe Santiago de Chile. Disponível em: http://www.eclac.org/ >. Acesso em: 11/2014.

CÉSAR, Gustavo Rojas de Cerqueira (2012). Mecanismos Regionais de Liquidez em Países em Desenvolvimento. Revisa Tempo do Mundo, 4 (3): 97-152.

DATHEIN, Ricardo (2007). Integração Econômica na América Latina: second Best ou estratégia regional de desenvolvimento? In: Encontro Nacional de Economia Política, 12, 2007, São Paulo, Anais. São Paulo: SEP, 2007.

DULLIEN, Sebastian et al (2013). Regional Monetary Cooperation: Lessons from the Euro Crisis for Developing Areas? World Economic Review 2.

FELÍCIO, Cesar (2011). "Mantega quer fundo de reservas para proteger países da UNASUL”. Valor Econômico, 11 de agosto. Disponível em:

http://www.valor.com.br/brasil/976470/mantega-quer-fundo-de-reservas-para-protegerpaises-da-unasul/> . Acesso em: março de 2017.

FERNANDES, Marcelo Pereira (2012) “O Papel de Supervisor do Fundo Monetário Internacional e a Crise Financeira do Subprime". Carta Internacional, vol. 7, n. 1, jan-jun. FERRAZ, Lucas (2011b). "Brasil quer Fundo latino-americano contra crise, diz Mantega". Folha de São Paulo, 11 de agosto. <Disponível em: http://www1.folha.uol.com.br/poder/958512-brasil-quer-fundo-latino-americano-contra-crisediz-mantega.shtml> . Acesso em: março de 2017.

FISCHER, Stanley (1987). International Macroeconomic Policy Coordination. Cambridge, Massachussets: National Bureau of Economic Research, 1987. (NBER Working Paper n. 2224).

FLAR (2015) Acerca del FLAR: Estructura de Capital del FLAR. Disponível em: https://www.flar.net/contenido/contenido.aspx? catID=138\&conID=5202 >. Acesso em: 02/2016.FLAR (2016). Convenio Constitutivo. Edición no 17, Abril. Disponível em: < http://www.flar.net/uploads/default/projects/79ca5aa9a7fbded0446b2d4a4fff6f04.pdf> . Acesso em: 05/2017

FRITZ, Barbara e MÜHLICH, Laurissa (2012). "Varieties of regional monetary cooperation: a tool for reducing volatility in developing economies?" Disponível em: http://daadpartnership.htw-

berlin.de/fileadmin/Workshops/2012_Berlin/Papers/Fritz_Muehlich_Varieties_RegionalMone taryCooperation_092012.pdf>. Acesso em: 11/2014.

FRITZ, Barbara e MÜHLICH, Laurissa (2006). "Regional Monetary Integration among Developing Countries: New Opportunities for Macroeconomic Stability beyond the Theory of Optimum Currency Areas?" GIGA Research Programme: Transformation in the Process of Globalisation, $\mathrm{n}^{\mathrm{0}} 38$. 
FURTADO, Fabrina (2008). Integração Financeira da América do Sul. Banco do Sul: mais do mesmo ou oportunidade histórica? Oikos, v.7, n.1, pp.173-190, 2008.

GIRALDI, Renata (2011). "Chávez defende criação de um fundo de reservas para a América Latina e o Caribe". Agência Brasil, 3 de dezembro. Disponível em:< http://memoria.ebc.com.br/agenciabrasil/noticia/2011-12-03/chavez-defende-criacao-de-umfundo-de-reservas-para-america-latina-e-caribe>. Acesso em: 02/2015.

GIRALDO, Carlos (2012). Fondo Latinoamericano de Reservas, 2012. Disponível em:< http://www.sela.org/attach/258/default/Di-

13_Presentacion_Fondo_Latinoamericano_de_Reservas_2012_\%28Carlos_Giraldo\%29.pdf>. Acesso em: 01/2015.

GONZÁLEZ, Carlemy (2012). Próximo reto de la integración sulamericana: um fondo común de reservas. Revista BCV • Vol. XXVIII, N 2, Caracas, julio-diciembre 2012.

MACHINEA, José Luis; TITELMAN, Daniel (2007), “¿Uncrecimiento menos volátil? El papel de las instituciones financeiras regionales", Revista de la CEPAL, 91, abril de 2007. OCAMPO, José Antonio (2006), "La cooperación financiera regional: experiencias y desafíos". In: OCAMPO, José Antonio (Org.).Cooperación financiera regional. Santiago de Chile, Comisión Económica para América Latina y el Caribe (CEPAL).

SAIM (Secretaria de Assuntos Internacionais) (2016). Relatório de Gestão - Exercício 2015. Ministério da Fazenda.

Disponível

em:http://www.sain.fazenda.gov.br/noticias/geral/relatorios-de-

gestao/relatorio_de_gestao_sain_2015.pdf >. Acesso em: 01/2017

SAIM (Secretaria de Assuntos Internacionais) (2015). Relatório de Gestão - Exercício 2014. Ministério da Fazenda. Disponível em:< http://www.sain.fazenda.gov.br/noticias/geral/relatorios-de-gestao/relatorio-de-gestao-sain2014> . Acesso em: 01/2017

SAIM (Secretaria de Assuntos Internacionais) (2012). Relatório de Gestão - Exercício 2011. Ministério da Fazenda. Disponível em: http://www.sain.fazenda.gov.br/noticias/sucex/relatorios-de-gestao-fge/relatorio-fge-2011>. Acesso em: 01/2017

TITELMAN, Daniel (2006). La cooperación financeira em elámbito subregional: las experiencias de América Latinay el Caribe. In: OCAMPO, José Antonio (Org.). Cooperación financiera regional. Santiago de Chile, Comisión Económica para América Latina y el Caribe (CEPAL).

TITELMAN, Daniel et al (2013) "Hacia una cobertura regional más amplia de um fondo de reservas". Serie Financiamiento para el desarrollo. CEPAL. Disponível em: <http://www.cepal.org/es/publicaciones/hacia-una-cobertura-regional-mas-amplia-de-unfondo-de-reservas $>$. Acesso em 02/2015.

VELARDE, Julio (2014). Las crisis financeiras y los mecanismos de protección: perspectivas del FLAR. In: PERRY, Guillermo.Construyendo um fondo latinoamericano de reservas. Los 35 años del FLAR. Bogotá, Fondo latinoamericano de reservas.

VERGARA, Rodrigo (2012). "Mesa redonda sobre el FLAR”. In: Regionalismo Financeiro y Estabilidad Macroeconómica. Papersand Proceedings, VI Conferencia Internacional de Estudios Económicos 2012. Dirección de Estudios Económicos. Fondo Latinoamericano de Reservas.

Disponível em:http://eprints.soas.ac.uk/17390/1/6420_Papers_and_proceedings_2012_COMPLETO.pdf> Acesso em: 03/2015.

YEYATI, Eduardo Levy (2012). Fondo Latinoamericano de Reservas: Diagnóstico y Recomendaciones. Documento de discusión No. 2. FLAR, set. 
FERNANDES, WEGNER

Recebido em agosto de 2017 Aceito em setembro de 2017. 